\title{
Tympanoplasty using wet temporalis fascia graft at tertiary care hospital
}

\author{
Santosh B. Mane ${ }^{1 *}$, Siddhartha S Shrivastava ${ }^{2}$, Siddartha N Oswal ${ }^{3}$, Apurva A. Jarandikar ${ }^{4}$, Sagarika S Satav ${ }^{5}$ \\ ${ }^{\mathbf{1}}$ Associate Professor, ${ }^{\mathbf{2 , 4}, \mathbf{5}}$ Senior Resident, ${ }^{\mathbf{3}}$ Assistant Professor, Dept. of ENT. ${ }^{\mathbf{1 , 2 , 4 , 5}}$ PCMC P G Institute Yashwantrao Chavan \\ Memorial Hospital, Pimpri-Chinchwad, Maharashtra, ${ }^{3}$ Shri Bhausaheb Hire Government Medical College, Dhule, Maharashtra, \\ India
}

*Corresponding Author: Santosh B. Mane

Email: drsantos1110@gmail.com

\begin{abstract}
Diagnosis of chronic otitis media implies a permanent abnormality of the pars tensa or flaccida, most likely result of earlier acute otitis media, negative middle ear pressure or otitis media with effusion. It results in some degree of conductive hearing loss due to perforated tympanic membrane with or without ossicular distruction. This condition is treated by tympanoplasty in which we do the repair of tympanic membrane with the help of temporalis fascia graft. In our study we used the wet temporalis fascia graft. We did an observational study of 40 cases of COM inactive Mucosal type and found that 39 cases had the better graft placement and shorter uptake time as well as the operative time. And also there was significant improvement in the hearing post operatively which was assessed by pure tone audiometry. However, a larger sample size would help further establish the validity or relevance of our study.
\end{abstract}

Keywords: COM, Tympanoplasty, Wet Temporalis Fascia Graft.

\section{Introduction}

Chronic otitis media implies a permanent abnormality of pars tensa or pars flaccida, most likely result of earlier acute otitis media, negative middle ear pressure or otitis media with effusion 1.

There are five sub types of chronic otitis media

1. Inactive mucosal COM- In this there is permanent perforation of pars tensa but middle ear mucosa is not inflamed.

2. Active mucosal COM- Permanent defect of pars tensa with an inflamed middle ear mucosa which produces mucopus that may discharge.

3. Healed COM-Thinning and/or local or generalised opacification of pars tensa without perforation or retraction.

4. Inactive squamosal COM- Retraction of pars flaccida or pars tensa (usually posteriosuperior) which has potential to become active with retained debris.

5. Active squamosal COM (Cholesteatoma)- Retraction of pars flaccida or pars tensa that has retained squamous epithelial debris and is associated with inflammation and production of pus. ${ }^{1}$

In mucosal type of COM, in active stage we give aural toileting, systemic and topical antibiotics, to make ear dry. As the ear becomes dry we can plan for surgery.

The term Tympanoplasty was introduced in 1953 by Wullstein. "Tympanoplasty is a procedure to eradicate disease in the middle ear cleft and to reconstruct hearing mechanism, with or without tympanic membrane grafting". ${ }^{2}$

Tympanoplasty is classified in to five different types, originally described by Wullstein.

Type 1 tympanoplasty involves repair of tympanic membrane alone, when the middle ear is normal. Type 1 tympanoplasty is synonymous to myringoplasty.

Reconstruction of tympanic membrane done using variety of graft materials like temporalis fascia, fascia lata, dura, tragal perichondrium, tragal cartilage ${ }^{3}$.
In tympanoplasty some surgeons harvest temporalis fascia at the start of procedure and use it when it becomes dry. Whereas other surgeons harvest at the time of putting the graft when it is wet or fresh graft. ${ }^{4}$

In 2009,Alken S, Baylancicek S, et al done the study on effect of use of dry or wet temporalis fascia graft in tympanoplasty. They found that using wet graft can shorten the operation time and graft placement time. ${ }^{5}$

In 2016 Singh G B,Kumar D done similar study to evaluate the success rate of dry and wet temporalis fascia graft in type 1 underlay tympanoplasty. They found that dry or wet graft, it doesn't influence the outcome of tympanoplasty. ${ }^{6}$

The basic aim of our study was to evaluate the success rate of wet temporalis fascia graft in type -1 tympanoplasty surgery.

\section{Aims and Objectives}

To study merits and demerits of using wet temporalis fascia graft in type - 1 tympanoplasty.

To study results of type -1 tympanoplasty using wet temporalis fascia graft in terms of graft uptake, hearing improvement and recurrence.

\section{Materials and Methods \\ Type of study \\ Prospective observational study}

Study group

Patients of COM Mucosal Inactive undergoing type-1 tympanoplasty.

\section{Place of study \\ Tertiary Care Hospital.}

Selection of patients

Patients with Inactive Mucosal COM. 


\section{Duration of study}

9 months

\section{Inclusion criteria}

1. Patients with Inactive COM mucosal type

2. All age groups

3. Both male and female

\section{Exclusion criteria}

1. Patients with active ear discharge

2. Squamosal com

3. Revision tympanoplasty

4. Poor compliance

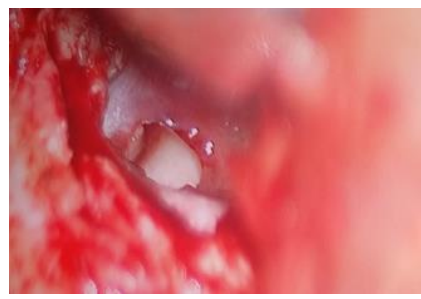

Fig. 1: Intra operative perforation of tympanic membrane.

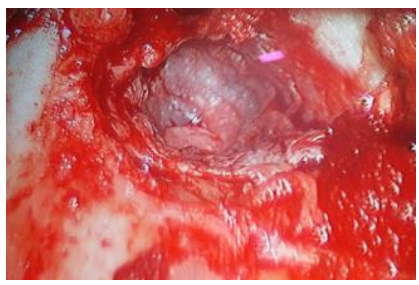

Fig. 2: Intra operative - After placement of graft.

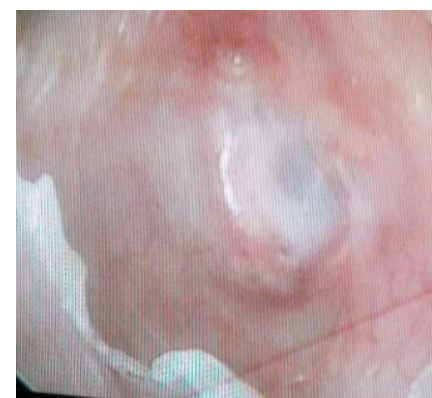

Fig. 3: Intact Tympanic Membrane post operative 24 weeks

Table 1: Age distribution of cases studied $(n=40)$.

\begin{tabular}{|c|c|c|}
\hline Age Group (years) & No. of cases & \% of cases \\
\hline$<20$ & 4 & 10.0 \\
\hline $20-29$ & 13 & 32.5 \\
\hline $30-39$ & 12 & 30.0 \\
\hline $50-49$ & 7 & 17.5 \\
\hline $50-59$ & 4 & 10.0 \\
\hline Total & 40 & 100.0 \\
\hline
\end{tabular}

Of 40 cases studied, $4(10.0 \%)$ had age less than 20 years, $13(32.5 \%)$ had age between $20-29$ years, $12(30.0 \%)$ had age between $30-39$ years, $7(17.5 \%)$ had age between $40-$ 49 years and $4(10.0 \%)$ had age above 50 years.
The mean \pm SD of age of the entire group of cases studied was $32.8 \pm 11.1$ years and the minimum - maximum age range was $16-55$

Table 2: Sex distribution of cases studied $(n=40)$.

\begin{tabular}{|c|c|c|}
\hline Sex & No. of cases & \% of cases \\
\hline Male & 21 & 52.5 \\
\hline Female & 19 & 47.5 \\
\hline Total & 40 & 100 \\
\hline
\end{tabular}

Of 40 cases studied, $21(52.5 \%)$ were males and $19(47.5 \%)$ were females. In the entire study group, the male to female sex ratio was 1.10: 1.00 .

Table 3: Distribution of operative side among the cases studied $(\mathrm{n}=40)$.

\begin{tabular}{|c|c|c|}
\hline Operative side & No. of cases & \% of cases \\
\hline Right & 21 & 52.5 \\
\hline Left & 19 & 47.5 \\
\hline Total & 40 & 100 \\
\hline
\end{tabular}

Of 40 cases studied, 21 (52.5\%) had right side operated and $19(47.5 \%)$ had left side operated in the study group.

Table 4: Distribution of laterality of the disease among the cases studied $(\mathrm{n}=40)$.

\begin{tabular}{|c|c|c|}
\hline Laterality & No. of cases & \% of cases \\
\hline Unilateral & 34 & 85.0 \\
\hline Bilateral & 6 & 15.0 \\
\hline Total & 40 & 100 \\
\hline
\end{tabular}

Of 40 cases studied, $34(85.0 \%)$ had unilateral disease and 6 $(15.0 \%)$ had bilateral disease in the study group.

Table 5: Distribution of mean graft harvesting time, graft placement time and total operating time among the cases studied $(\mathrm{n}=40)$.

\begin{tabular}{|c|c|c|c|}
\hline & \multicolumn{3}{|c|}{ Time (Mins) } \\
\hline & Mean & SD & Min - Max \\
\hline Graft harvesting time & 4.72 & 0.90 & $4-7$ \\
\hline Graft placement time & 4.72 & 1.36 & $3-8$ \\
\hline Total operating time & 49.28 & 4.58 & $40-60$ \\
\hline
\end{tabular}

The mean \pm SD of graft harvesting time was $4.72 \pm 0.90$ mins and the min - max time range was $4-7$ mins.

The mean \pm SD of graft placement time was $4.72 \pm$ 1.36 mins and the min - max time range was $3-8$ mins.

The mean \pm SD of total operating time was $49.28 \pm$ 4.58 mins and the min - max time range was $40-60$ mins.

Table 6: Distribution of mean pre-op and post-op hearing score (AB GAP) among the cases studied $(n=40)$.

\begin{tabular}{|l|c|c|}
\hline \multicolumn{2}{|c|}{ AB GAP (dB) } \\
\hline Pre-op & Mean & SD \\
\hline Post-op 3-Months & 38.63 & 6.09 \\
\hline Post-op 6-Months & 28.75 & 6.67 \\
\hline \% Improvement at 3-Months & 22.00 & 7.49 \\
\hline \% Improvement at 6-Months & $24.82 \%$ & \\
\hline P-value (Paired data) & $42.84 \%$ & \\
\hline Pre-op v Post-op 3-Months & \\
\hline Pre-op v Post-op 6-Months & $0.001^{* * *}$ & \\
\hline $\begin{array}{l}\text { P-value by paired t test. P-value }<0.05 \\
\text { statistically significant. ***P-value }<0.001 .\end{array}$ & $0.001^{* * *}$ considered to be \\
\hline
\end{tabular}


The mean \pm SD pre-op and post-op 3-months AB GAP was $38.63 \pm 6.09 \mathrm{~dB}$ and $28.75 \pm 6.67 \mathrm{~dB}$. Distribution of mean post-op 3-months AB GAP is significantly lower (improved) compared to mean pre-op AB GAP (Pvalue $<0.00)$. The $\%$ improvement in the $\mathrm{AB}$ GAP at 3months from the pre-op stage was $24.82 \%$.

The mean \pm SD pre-op and post-op 6-months AB GAP was $38.63 \pm 6.09 \mathrm{~dB}$ and $22.00 \pm 7.49 \mathrm{~dB}$. Distribution of mean post-op 6-months $\mathrm{AB}$ GAP is significantly lower (improved) compared to mean pre-op $\mathrm{AB}$ GAP (Pvalue $<0.00)$. The $\%$ improvement in the $\mathrm{AB}$ GAP at 6months from the pre-op stage was $42.84 \%$.

Table 7: Distribution of pre-op and post-op outcome of Rinne's test among the cases studied $(n=40)$.

\begin{tabular}{|c|c|c|c|c|c|c|c|}
\hline & \multicolumn{4}{|c|}{ Post-op (Rinne's test) } & \multirow{2}{*}{\multicolumn{2}{|c|}{ Total }} & \multirow[b]{3}{*}{ P-value } \\
\hline & \multicolumn{2}{|c|}{ Positive } & \multicolumn{2}{|c|}{ Negative } & & & \\
\hline $\begin{array}{l}\text { Pre-op } \\
\text { (Rinner's } \\
\text { test) }\end{array}$ & $\mathrm{n}$ & $\%$ & $\mathrm{n}$ & $\%$ & $\mathrm{n}$ & $\%$ & \\
\hline Positive & 1 & 100.0 & 0 & 0.0 & 1 & 100.0 & $0.736^{\mathrm{NS}}$ \\
\hline Negative & 35 & 89.7 & 4 & 10.3 & 39 & 100.0 & \\
\hline Total & 36 & 90.0 & 4 & 10.0 & 40 & 100.0 & \\
\hline
\end{tabular}

Of 1 Positive case pre-operatively, $1(100.0 \%)$ had positive post-op Rinne's test and none had negative post-op Rinne's test. Of 39 Negative cases pre-operatively, 35 (89.7\%) had positive post-op Rinne's test and $4(10.3 \%)$ had negative post-op Rinne's test. The overall Post-op \% improvement in Rinne's test was $89.7 \%$.

Distribution of Post-op Rinne's test improved significantly compared to Pre-op Rinne's test (Pvalue<0.001).

Table 8: Distribution of uptake of graft among the cases studied $(\mathrm{n}=40)$.

\begin{tabular}{|c|c|c|c|c|c|c|}
\hline & \multicolumn{4}{|c|}{ Uptake of graft } & \multicolumn{2}{c|}{} \\
\hline & \multicolumn{2}{|c|}{ Yes } & \multicolumn{2}{c|}{ No } & \multicolumn{2}{c|}{ Total } \\
\hline Follow-up & $\mathrm{n}$ & $\%$ & $\mathrm{n}$ & $\%$ & $\mathrm{n}$ & $\%$ \\
\hline 4-Weeks & 14 & 35.0 & 26 & 65.0 & 40 & 100.0 \\
\hline 12-Weeks & 36 & 90.0 & 4 & 10.0 & 40 & 100.0 \\
\hline 24-Weeks & 39 & 97.5 & 1 & 2.5 & 40 & 100.0 \\
\hline
\end{tabular}

Of 40 cases studied, 14 (35.0\%) had uptake of graft and 26 $(65.0 \%)$ did not have it at 4-weeks.

Of 40 cases studied, $36(90.0 \%)$ had uptake of graft and $4(10.0 \%)$ did not have it at 12 -weeks.

Of 40 cases studied, 39 (97.5\%) had uptake of graft and $1(2.5 \%)$ did not have it at 24-weeks.

\section{Discussion}

This study mainly focuses on surgical outcome and audiological improvement in the patients undergoing type 1 tympanoplasty using wet temporalis fascia graft.

In our study, we used wet temporalis fascia graft i.e. we harvested the graft just before putting it. Although initially it is a little difficult to put wet temporalis fascia graft as it gets rolled. Using an operating microscope, harvesting graft becomes easy and comfortable, as you can take only the temporalis fascia without any muscle or soft tissue.

In 2009, Alkan S et al studied the effects of use of dry vs wet temporalis fascia graft on tympanoplasty they found that using wet graft can shorten the operative time and result in a high number of fibroblast nuclei histologically. ${ }^{5}$

In our study, among 40 cases studied, total mean operative time was $49.28+/-4.58 \mathrm{~min}$. graft harvesting time was $4.72+/-0.97 \mathrm{~min}$ and graft placement time was $4.72+/-$ $1.36 \mathrm{~min}$.

In our study, of the 40 cases studied, 36 cases (90\%) had uptake of graft at 12 weeks and at the end of 24 weeks 39 cases $(97.5 \%)$ had graft uptake.

Regarding the audiological result, the mean +/- SD pre -operative and post - operative 6 months $\mathrm{AB}$ gap was 38.63 $+/-6.09 \mathrm{~dB}$ and $22.00+/-7.49 \mathrm{~dB}$.

We found statistically significant improvement in hearing i.e. percentage improvement in the $A B$ gap at 6 months from the pre - operative stage was $42.84 \%$ ( $\mathrm{p}<$ 0.001). Also post operative Rinne's test improved significantly $(\mathrm{p}<0.001)$.

\section{Conclusion}

Our study suggests that using wet temporalis fascia graft can improve the results of type-1 tympanoplasty in terms of hearing outcome and graft uptake. Also using wet graft we can shorten the operative time.

Though the present study does not have a large number of cases, evidence is provided that using wet temporalis fascia graft is of valid consideration in tympanoplasty.

\section{Source of funding}

None.

\section{Conflict of interest}

None.

\section{References}

1. George G. Browning, Scott Brown's Otorhinolaryngology and Head \& Neck surgery, $8^{\text {th }}$ Edition ;3;977-1021.

2. Wullstein, H. (1956), Theory and practice of tympanoplasty. Laryngoscope 1956;66:1076-93. doi:10.1288/00005537195608000-00008

3. Ian RC Swan, Richard Canler, Scott Brown's Otorhinolaryngology and Head \& Neck surgery, $7^{\text {th }}$ edition;vol3;3400-21

4. Vikram B, Verma R, Novel method of drying temporalis fascia graft for tympanomastoid surgery. Indian J Otology 13013;19(2);66-7.

5. Alkan S, Baylanĉice ek S. Effect of the use of dry (rigid) or wet (soft) temporal fascia graft on tympanoplasty, J Otolaryngol Head Neck Surg 2009;38(1):126-32.

6. Singh GB1, Kumar D. Tympanoplasty: does dry or wet temporalis fascia graft matter?, J Laryngol Otology 2016;130(8):700-5.

How to cite: Mane SB, Shrivastava SS, Oswal SN, Jarandikar AA, Satav SS. Tympanoplasty using wet temporalis fascia graft at tertiary care hospital. IP J Otorhinolaryngol Allied Sci 2020;3(1):23-5. 